\title{
KONTRIBUSI TEOSOFI TRANSENDENTAL MULLA SADRA BAGI PENDIDIKAN AGAMA ISLAM
}

\author{
Miswari \\ Email : miswari@iainlangsa.ac.id \\ Dosen IAIN Langsa
}

\begin{abstract}
Abstrak
Tulisan ini bertujuan mengeksplorasi gagasan metafisika Mulla Sadra dan menarik nilai ajaran tersebut sebagai nilai bagi pelajaran aqidah dalam pendidikan agama Islam. Penulis melakukan eksplorasi gagasan metafisika Mulla Sadra dari berbagai referensi, menghadirkannya dalam bentuk narasi baru yang lebih riskan dan selanjutnya menarik intisari gagasan tersebut. Tulisan ini menunjukkan bahwa gagasan metafisika Mulla Sadra yang lebih familiar disebut dengan Teosofi transcendental yang berbasis kepada kemendasaran wujud atas mahiyah, gradasi wujud dan identitas sederhana adalah segala sesuatu, dengan menyederhanakannya dalam konsep yang mudah dipahami, dapat ditawarkan sebagai pendekatan baru bagi pendidikan agama Islam, khususnya dalam pelajaran aqidah.
\end{abstract}

Keyword: Mulla Sadra, Pendidikan Islam, Pelajaran Aqidah,

\section{A. PENDUAhuluan}

Berbagai persoalan pendidikan yang dialami bangsa Indonesia sebenarnya dapat diatasi dengan merubah sudut pandang tentang manusia. Karena pemahaman yang benar tentang fitrah manusia merupakan kunci suksesnya pelaksanaan pendidikan. Banyak konsep dan teori tentang fitrah ditawarkan sebagai landasan pendidikan. Tetapi sudah benarkah pemahaman terhadap fitrah tersebut?

Tulisan ini menawarkan gagasan fisafat yang dibangun Mulla Sadra sebagai landasan pendidikan agama Islam, khususnya untuk pelajaran aqidah. Penulis menawarkan konsep-konsep inti dari pemikiran Mulla sadra seperti konsep wujûd, perbedaan wujûd dengan mahiyah, ashalat al-wajud dan i'tibar al-mahiyah, tasykik alwujûd dan al-harakah al-Jawhariyah.

Penulis berusaha mengeksplorasi gagasan-gagasan inti dari pemikiran Mulla sadra untuk dapat ditawarkan sebagai alternatif ataupun pengayaan bagi paradigma, 
kurikulum, pelaksanaan dan indicator penilaian bagi pendidikan agama Islam. Penuis menilai, pelaksanaan pendidikan agama islam di sekolah dan madrasah belum menemukan sebuah landasan yang jelas, rasional dan relevan dengan prinsip dasar kemanusiaaan. Untuk itu, pemikiran Mulla Sadra diharapkan dapat menjadi sebuah inspirasi untuk menyelesaikan persoalan-persoalan tersebut.

\section{B. FILSAFAT MULLA SADRA}

\section{Konsep Wujûd}

Wujûd sebagai mafhîm adalah gagasan prakonseptual yang terbukti dengan sendirinya (badihi). Tanpa gagasan ini, kita tidak dapat memahami apapun selainnya. . Wujûd yang terbukti dengan sendirinya dipahami melalui mawjîd yang dipahami pada setiap esensi (mahiyah) yang hadir ke dalam pikiran. ${ }^{2}$ Hanya dengan cara ini wujûd dijelaskan. Wujud sebagai konsep adalah hal yang paling disa diterapkan kepada apapun bahkan kepada konsep negasi atasnya yakni ketiadaan. ${ }^{3}$ Tetapi realitas sejati wujûd adalah hal yang paling sulit (atau bahkan mustahil) untuk dijelaskan.

Para filosof berusaha mengonseptualisasikan wujûd melalui analisa terhadap realitas eksternal yang terindrai. Pada realitas eksternal, antara suatu hal dengan keberadaannya tidak dapat dibedakan. Perbedaannya hanya muncul di dalam pikiran. Di alam eksternal, predikat tidak memberi tambahan kepada subjek. "Manusia ada" pada alam eksternal adalah gambar utuh tentang manusia. Tetapi di dalam pikiran, konsep wujûd menjadi konsep yang kaya karena dapat diterapkan kepada setiap esensi sekalipun dia berbeda dengan esensi. Sementara Wujûd Universal adalah sesuatu paling sederhana melampaui substansi yang tidak dapat dijelaskan kecuali melalui konsep wujûd dia menjadi paling kaya karena dapat diterapan kepada setiap quiditas (mahiyyah) meski berbeda dengan mahiyah. ${ }^{4}$

\footnotetext{
${ }^{1}$ Toshihiko Isutzu, Struktur Metafisika Sabzawari, (Bandung: Pustaka, 2003), h. 18

2 Toshihiko Isutzu, Struktur Metafisika Sabzawari, h. 22

3 Mehdi Haeri Yazdi, Menghadirkan Cahaya Tuhan: Epistemologi Illuminasionis dalam Filsafat Islam, (Bandung: Mizan, 2003), h. 71

${ }^{4}$ Toshihiko Isutzu, Struktur Metafisika Sabzawari, (Bandung: Pustaka, 2003), h. 32
} 


\section{Perbedaan Wujûd dengan Mahiyah}

Pembahasan tentang perbadaan antara wujûd dengan mahiyah adalah pembahasan primordial dalam sejarah filsafat. Islam. Pembahasan ini diwariskan kepada para filosof Barat abad pertengahan. Pembahasan ini dikenal sebagai ciri khas al-Farabi dan Ibn Sina. ${ }^{5}$ Sekalipun pembahasan ini telah disinggung oleh Aristoteles, tetapi diperjelas oleh kedua filosof Masya'iyah tersebut dan respon juga oleh filosof Muslim selanjutnya seperti Nasr al-Dis Thusi, Mulla Sadra, Hadi Sabzawari dan lainlain.

Pada realitas alam eksternal, kita hanya menemukan fenomena'fenomena (mawjûd) seperti kuda, manusia, batu, air dan sebagainya. Kenyataannya setiap hal tersebut terdiri dari esensi (mahiyah) dan esse (wujûd). Karena setiap hal tersebut mengandung eksistensi, maka dapatlah disebut 'kuda ada', 'air ada' dan sebagainya. Kesamaan mereka adalah karena semuanya memiliki eksistensi (wujûd) sementara quiditas masing masing berbeda: quiditas kuda tidak dapat diterapkan pada quiditas air, dan seterusnya. ${ }^{6}$

\section{Ashalat al-Wajud dan I'tibar al-Mahiyah}

Melalui kajian atas perbedaan antara wujûd dengan mahiyah, kajian diteruskan oleh para filosof untuk mengkaji yang manakah diantara dua hal tersebut yang lebih mendasar (ashal). Kemunkinan hanyalah pada satu diantara kedua hal tersebut. Maksudnya, bila mahiyah yang ashal, maka wujûd adalah i'tibar. Sebaliknya bila wujûd yang ashal, maka mahiyah yang i'tibar. ${ }^{7}$ Filosof yang memegang keutamaan wujûd atas mahiyah seperti Mulla Sadra dan Hadi Sabzawari. Sementara yang memagang keutamaan mahiyah atas wujûd seperti Syihab al-Din Suhrawardi dan Mir Damad. Sebenarnya ada juga yang meyakini keduanya yakni wujûd dan esensi sekaligus adalah ashal yakni Ahmad Ahsa'i, tetapi karena argumentasinya sulit dipertahankan. ${ }^{8}$ maka kurang mendapat perhatian para pengkaji filsafat.

\footnotetext{
5 Toshihiko Isutzu, Struktur Metafisika Sabzawari, (Bandung: Pustaka, 2003), h. 37

6 Toshihiko Isutzu, Struktur Metafisika Sabzawari, (Bandung: Pustaka, 2003), h. 38-39

7 Toshihiko Isutzu, Struktur Metafisika Sabzawari, (Bandung: Pustaka, 2003), h. 54

${ }^{8}$ Toshihiko Isutzu, Struktur Metafisika Sabzawari, (Bandung: Pustaka, 2003), h. 55
} 
Mahiyah terbagi dua yakni mahiyah sebagai sesuatu yang menjadi jawaban terhadap 'apa itu' atau disebut sebagai mahiyah dalmpengertian khusus. Sementara mahiyah seagai realitas hakikat segala sesuatu yang darinya sesuatu diterapkan adalah mahiyah dalam pengertian umum. Bagi penganut ashalatul mahiyah, mahiyah secara umum adaah sama dengan wujûd. Tetapi penganut shlatul wujûd tidak sependapa egan hal ini. Bagi penganut ashalatul wujûd, sesuatu yang ashal harus "... Mempunaikeutamaan atas segala hal dalam memiliki 'esensi' karena'yang sejati' dalam pengetian yang utu dan mutlak." demikian Toshihiko Isutzu ${ }^{9}$ menulis.

Bermula perdebatan manakah yang ashil antara wujûd dan mahiyah karena ketika suatu objek masuk ke dalam pikiran, batu misalnya, muncullah dua hal yakni kebatuan dan eksistensi batu. Hal ini tentunya hanya berlaku di dalam pikiran karena jelas pada satu hal pada realitas alam di luar, tidak mungkin terdiri dua hal sekaligus. Manakah yang lebih utama di dalam pikiran, maka itulah yang related dengan yang ada di alam. Bagi penganut aslalat al-wujûd, yang related dengan alam adalah wujûd. ${ }^{10}$ Dalam paham ini, quiditas tampaknya ashal di dalam pikiran hanyalah semacam pembatas bagi eksistensi yang meliputi segalahal pada alam, yang dengannyalah eksistensi dapat hadir ke dalam pikiran. Quiditas batu yang kita anggap sebagai sesuatu yang kokoh dan berdiri sendiri pada kenyataannya ternyata adalah wujûd yang tak terbatas yang melakukan tindakan mengada sendiri melalui limitasi diri sehingga menjadi sebuah batu. Esensi dalam pandangan penganut ashalat al-wujûd yakni Mulla Sadra adalah bayangan bayangan, cerminan atau kiasan bagi wujûd. Pandangan ini sejalan dengan ajaran Ibn 'Arabi yang mengatakan segala fenomena di alam adalah bayangan dari Wajib al-Wujûd. ${ }^{11}$ Karena dalam paham ini melihat sesungguhnya segala sesuatu adalah penampakan dari Wujûd yang Tunggal, sebab itulah mereka digolong sebagai penganut wahdah al-Wujûd. Paham ini sejalan dengan paham yang dianun kaum sufi.

\footnotetext{
9 Toshihiko Isutzu, Struktur Metafisika Sabzawari, (Bandung: Pustaka, 2003), h. 58

${ }^{10}$ Toshihiko Isutzu, Struktur Metafisika Sabzawari, (Bandung: Pustaka, 2003), h. 57

${ }^{11}$ William C. Chittick, Dunia Imajinal Ibnu 'Arabi, diterjemahkan dari Imaginal Worlds oleh Achmad Syahid, (Surabaya: Risalah Gusti, 2001), h. 33
} 
Apabila mahiyah yang ashil, maka setiap entitas dialam satu sama lain akan berbeda sama sekali. Tidak akan ada pada aspek apapun untuk ditemukan kesamaannya. Bila demikian maka tindakan penilaian biasa atau predikasi teknik umum (haml syay'i shina'i) karena ini hanya dapat dilakukan apabila terdapat kesamaan sekaligus perbedaan. Perbedaannya tentu adalah karena mahiyyah dan persamaanny adalah karena wujûd. Misalnya manusia menulis. ${ }^{12}$ Subjeknya adalah manusia dan predikatnya adalah menulis. Di alam, hanya ditemukan satu hal yakni manusia, tetapi di dalam pikiran terdapat perbedaan antara quiditas manusia dan menulis. Dari sisi quiditas, konsep manusia dan konsep menulis adalah berbeda. Tetapi dari sisi wuju adalah sama. Aspek perbedaan pada sisi wujûd adalah perbedaan tingkatan. Tetapi kalau saja yang ashil adalah mahiyah, maka tentu persamaan antar tiap quiditas berbeda sehingga tidak dapat dibentuk sebuah predikasi karena ketiadaan hubungan antar tiap quiditas. Karena itu, tidak dapat disangkal bahwa sesungguhnya wujûdlah yang ashil dan mahiyah hanyalah i'tibar. Quiditas hanyalah bayang-bayang semata.

\section{Tasykik al-Wujûd}

Hanya dengan penerimaan wujûd yang ashal dan mahiyah hanya i'tibar kita dapat menggunakan tasykik al-wujûd. Sebab, tasykin al-wujûd hanya berlaku bila terdapat aspek kesamaan sekaligus perbedaan dalam wujûd. Terdapat empat syarat untuk terjadinya tasykik al-wujûd yakni kesatuan wujûd alah aktual, pluralitas wujûd adalah aktual, pluralitas wujûd akan kembali kepada kesatuan dan kesatuan mengalir dalam pluralitas. ${ }^{13}$

Dalam tasykik al-wujûd, asper persamaannya adalah perbedaannya. Dalam hal ini kesamaannya adalah wujûd dan perbedaannya adalah wujûd. Misalnya antara cahaya lilin dan cahaya matahari. Persamaannya adalah pada cahaya dan perbedaannya adalah pada cahaya juga. Dalah hal ini perbedaannya adalah pada kualitas cahaya itu sendiri. Selanjutnya pada satu entitas harus memiliki mishdaq atau

\footnotetext{
12 Toshihiko Isutzu, Struktur Metafisika Sabzawari, (Bandung: Pustaka, 2003), h. 57

${ }^{13}$ Muhammad Nur. Wahdah al-Wujûd Ibn 'Arabi dan Filsafat Wujûd Mulla Sadra, (Makassar: Chamran Press, 2012), h.71
} 
objek acuan yang berbeda. Seperti pada contoh cahaya tadi, perbedaannya adalah pada sisi kuat dan lemahnya cahaya. Hal paling penting adalah, aspek kesatuaannya adalah aspek kesamaan itu sendiri.

Terdapat beberapa dalil dalam membuktikan konsep tasykil al-wujûd. Yakni pluralitas eksistensi yang terindrai; hal ini bersifat badihi atau aksioma, tanpa perlu diberi dalil. Dalil selanjutnya adalah tidak ditemukannya perbedaan total sebab kalau saja perbedaan total pada realitas indrawi maka tentu akan melahirkan perbedaan yang tidak memiliki unsur apapun untuk menyamakannya. Kerana itu jelaslah bahwa perbedaan yang terindra di alam bukan perbedaan esensi tetapi hanya perbedaan gradasi. Dalil terakhir adalah wujûd yang terindrai di alam ada wujûdnya yang lebih kuat dan lebih lemah dan ada wujûd yang lebih dahulu dan lebih akhir. Perbedaan wujûd ini adalah pada tasykiknya. ${ }^{14}$

\section{Al-Harakah Al-Jawhariyah}

Sebelum Mulla Sadra, para filosof meyakini bahwa gerak terjadi hanya pada aksiden dari suatu entitas. Ibn Sina mengatakan, gerak terjadi pada perubahan dari tiga aksiden yaitu kualitas, kuantitas, tempat dan posisi. Sementara bila ada perubahan seketika dari satu entitas menuju entitas yang lain, yang tentunya melibatkan perubahan pada substansinya, maka oleh filsafat peripatetik tidak disebut sebagai gerak tetapi disebut dengan kejadian dan kehancuran (al-kawn wa al-fasad).

Perubahan seketika dari satu entitas ke entitas lain oleh filosof peripatetik tidak diasumskan terjadi dalam waktu karena mereka telah menegasikan kontinuitas antara satu entitas dengan entitas lain. Tetapi Mulla Sadra tidak sependapat. Menurutnya, perubahan seketika juga harus disebut dengan gerak, terdapat kontinuitas antara satu entitas dengan entitas baru yang berubah semacam itu itu. Menurut Mulla Sadra, gerak tidak hanya terjadi pada aksiden namun juga substansi. Bahkan menurutnya, perubahan pada aksiden itu adalah konsekuensi dari perubahan substansi ${ }^{15}$.

\footnotetext{
${ }^{14}$ Muhammad Nur. Wahdah al-Wujûd Ibn 'Arabi dan Filsafat Wujûd Mulla Sadra, (Makassar: Chamran Press, 2012), h. 73

15 Murtadha Muthahhari, Filsafat Hikmah: Pengantar Pemikiran Sadra, Bandung: Mizan, 2002, h. 96.
} 
Menurut Ibn Sina, substansi mustahil bergerak karena menyebabkan perubahan esensi entitas yang berkonsekuensi pada ketiadaan subjek penopang gerak. Bila esensi bergetak, berarti tidak ada jarak karena jarak adalah kategori kuantitas pada suatu esensi. Dan bila jarak tidak ada, berarti dimensi waktu juga tiada. Tetapi Menurut Mulla Sadra, pemisahan dua entitas hanya berlaku pada ranah mental. Kejadian dan kehancuran tidak ada para realitas eksternal. Yang ada adalah perubahan esensi yang terjadi terus-menerus karena substansi yang terus bergerak berkonsekuensi pada perubahan aksiden ${ }^{16}$. Dalam prinsip filsafat Mulla Sadra, yakni ashalat al-wujud, esensi hanyalah respektifal dan yang nyata hanya wujûd, maka gerak substansi adalah gerak wujud.

Alam terbentuk dari manifestasi cahaya wujûd menuju arketip-arketip sehingga muncullah beragam mawjûd. Manifestasi ini disebut dengan pancara menurun (alqaus al-nuzulî). Pancara ini merupakan rangkaian mabda' yang membentuk berbagai maujud seperti akal, jiwa dan materi. Selanjutnya dengan pancaran menaik (al-qaws al-syu'udî) dengan tahap awalnya yakni perolehan bentuk oleh materi primer untuk mengaktual sebagai proses kesempurnaan hingga batasnya masing-masing. Gerak substansi terjadi pada pancaran menaik karena gerak substansi adalah gerak pada wujûd $d^{17}$.

Dalam pandangan Peripatetik, khususnya Aristoteles dan Ibn Sina. Jiwa dan tubuh adalah dua entitas terpisah. Hubungan antara dua entitas itu dijawab dengan konsep al-rûh al-bukharî oleh Ibn Sina. Tetapi konsep ini menciptakan sebuah masalah baru dalam filsafat. Maksudnya, al-rûh al-bukharî tidak memadai bila dianggap sebagai penghubung esensi jiwa dan esensi jasad. Harus ada juga penghubung al-rûh al-bukharî dengan tubuh dan penghubung al-rûh al-bukharî

${ }^{16}$ Seyyed Hossein Nasr, Ensiklopedi Tematis Filsafat Islam Buku kedua (Bandung, Mizan, 2003) h. 919. 
dengan jiwa. Keterbutuhan terhadap penghubung ini tidak akan berakhir sehingga meniscayakan terjadinya daur yang merupakan kemustahilan dalam filsafat ${ }^{18}$.

Mulla Sadra hadir untuk menyelesaikan persoalan ini. Menurutnya, jiwa dan tubuh bukan dua esensi berbeda melainkan satu entitas yang bergradasi. Jiwa dan jasad adalah satu kesatuan wujud yang henya berbeda pada gradasinya. Tubuh adalah aktualitas dari jiwa. Perubahan pada tubuh adalah aktualitas dari perubahan jiwa yang bergerak secara substansial. Jiwa memiliki tiga fakultas yakni inderawi yang diemban oleh tubuh, fakultas imajinasi yang merupakan aktualitas jiwa dalam bentuk dan fakultas inteleksi yang merupakan makna yang terlepas dari penginderaan dan imajinasi. Indera, imajinasi dan inteleksi semuanya bukan menjadikan jiwa sebagai lokus, tetapi adalah aktualitas jiwa ${ }^{19}$.

Eksistensi jiwa yang memiliki berbagai ragan tingkatan aktivitas yang dikonsepkan Mulla Sadra bersandar pada teori hakikat sederhana segala sesuatu (basith al-haqiqah kullî al-asya'), yakni wujûd sebagai entitas sederhana sekaligus meliputi segala sesuatu. Dan perlu diingat bahwa jiwa adalah wujûd.

\section{TEOSOFI MULLA SADRA}

Mengkaji konsep ketuhanan Mulla Sadra menjadi menarik karena konsep yang dia bangun sangat berbeda dengan filosof, sufi dan teolog sebelumnya. Prinsip Mulla Sadradalam konsep ketuhanan adalah, Tuhan hanya bisa dikenali melalui Diri-Nya saja $^{20}$. Mulla Sadramengkritik para pemikir sebelumnya karena mereka mengkaji Tuhan selalu melalui selain Dia. Bagi Mulla Sadra, Wujud Tuhan adalah lebih jelas dibandingkan dengan wujud-wujud selain-Nya. Maka upaya menjelaskan Tuhan melalui wujud-wujud selain Dia malah semakin mengaburkan pemahaman tentang Dia.

18 Mulyani, Gerak Trans-Substansial dan Implikasinya Terhadap Relasi Jiwa dan Tubuh dalam Al-Hikmah Al-Muta'alliyah, Tesis, (Jakarta: ICAS-Paramadina, 2014), h. 7-8

19 Mulyani, Gerak Trans-Substansial dan Implikasinya Terhadap Relasi Jiwa dan Tubuh dalam Al-Hikmah Al-Muta'alliyah, h. 9

${ }^{20}$ Fazlur Rahman, Filsafat Sadra, terj. Munir A. Mu'in, (Bandung: Pustaka, 2000), h. 165 
Ibn 'Arabî mengatakan, untuk menjelaskan al-Haqq, hanya bisa dilakukan dengan mengacu pada selain diri-Nya. Pandangan demikian sejalan dengan pendapat Ibn Sînâ. Menurutnya, sesuatu hanya bila diketahui melalui negasi. Sementara Mulla Sadratidak menerima pandangan seperti itu. Dalam pemikiran Mulla Sadra, Realitas adalah Wujud (Wujûd). Karena itu eksistensi realitas mustahil dinegasikan. Realitas menghimpun segalanya. Segala hal berada di dalam Realitas. Karena meliputi segala hal, maka Realitas adalah sesuatu yang paling jelas. Realitas menjadi jelas dengan dirinya sendiri. Realitas yang dimaksud ini dalam bahasa teologi disebut dengan Tuhan. Tidak mungkin mejelaskan realitas dengan seseatu di luar realias.

Dalam pandangan Mulla Sadra, realitas itu tunggal sekaligus beragam. Keberagamannya adalah pada ketunggalan dan ketunggalannya adalah keberagaman. Karena realitas Itu plural, sekaligus tunggal, maka akan tampak pemikiran Mulla Sadraini sebagai sebuah ambiguitas. Ambiguitas ini adalah prinsip ajaran tasykik alwujûd, yang dirumuskan Mulla Sadra. Dalam konsep ini, prinsipnya ada empat yaitu (1) pluralitas adalah pasti, (2) kesatuan adalah pasti, (3) Setiap pluralitas akan kembali pada kesatuan, dan (4) kesatuan mengalir dalam pluralitas. ${ }^{21}$ Prinsip ini memang banyak dinilai oleh para pengkaji Mulla Sadrasebagai subuah inkonsistensi.Tetapi demikianlah Mulla Sadramembangun fondasi pemikiran metafisikanya. Bila tidak menyepakati prinsip ini maka seluruh pemikiran Mulla Sadraakan tertolak, demikian pula sebaliknya.

Dalam membangun sistem tasykik al-wujûd, Mulla Sadrapunya argumentasi dan bukti-bukti yang amat sulit dibantah. Bahkan bila diteliti lebih jauh, maka sistem wujûd demikian yang dibangun Mulla Sadradapat dengan mudah dipakai untuk mematahkan argumentasi para penganut kemendasaran esensi (ashalat al-mahiyah). Kalau mahiyah (esensi) hanya bisa diterapkan pada satu entitas saja, maka wujûd dapat diterapkan pada setiap esensi (mahiyah). Prinsip demikian diakui Mulla Sadratidak sekedar suatu konsep (mafhum) tetapi adalah realitas yang sebenarnya. Pada realitas eksternal, yang hanya hanyalah wujûd yang satu sekaligus beragam.

${ }^{21}$ Muhammad Nur, Wahdah al-Wujûd Ibn 'Arabi dan Filsafat Wujud Sadra, (Makassar: Chamran Press, 2012), h. 71 
Prinsip wujûd yang bergradasi (tasykik) ini digunakan Mulla Sadradengan mengambil semangat dari prinsip manifestasi cahaya dalam filsafat Syihab al-Dîn Suhrawardî. Bagi Syihab al-Dîn Suhrawardî, suatu esensi memiliki hirarki. Suatu esensi, menurut Syihab al-Dîn Suhrawardî, memiliki tingkatan yang beragam, seperti cahaya misalnya. Mulla Sadrasepakat dengan manifestasi ini. Tetapi Mulla Sadratidak sepakat dengan Syihab al-Dîn Suhrawardî yang menyatakan bahwa esensi adalah yang menjadi fondasi realitas. Bagi Mulla Sadrayang mendasar adalah wujûd, bukan mahiyah (esensi). Esensi manusia misalnya, adalah manusia secara total, tidak kurang tidak lebih, tidak bergradasi.

Dalam pandangan Mulla Sadra, hanya wujûd yang dapat memiliki tingkatan seperti lebih dan kurang, awal dan akhir dan sebagainya. Mahiyah, bagi Mulla Sadrastatusnya fixed. Sementara yang dinamis dan bergerak secara terus-menerus hanya mungkin pada wujûd, bukan esensi. ${ }^{22}$

Bagian lain yang menjadi sistem bagian penting dalam metafisika Mulla Sadraadalah mengenai kritiknya terhadap konsep ketuhanan yang dibangun oleh filosof sebelum dirinya seperti Ibn Sînâ dan pengikutnya. Argumentasi terkenal para filosof sebelum Mulla Sadraadalah mengakui secara vertikal Tuhan sebagai sebab yang tidak diakibatkan dari rangkaian kausalitas temporal. Dalam sistem kausalitas yang dibangun Mulla Sadra, akibat tidak memiliki eksistensi sama sekali. Eksistensi akibat hanyalah dari eksistensi sebab semata tanpa keterpisahan sama-sekali. Akbat bagi Mulla Sadraadalah seperti predikat dalam sebuah kalimat. Predikat secara mutlak bergantung pada subjek.

Prinsip kausalitas untuk membuktikan Tuhan melalui kacamata peripatetik benar-benar tidak dapat diterima Mulla Sadra. Fazlur Rahman ${ }^{23}$ menjelaskan, prinsip kausalitas peripatetik yang mengklaim Tuhan sebagai penyebab tanpa disebabkan oleh apapun bertentangan dengan prinsip kausalitas itu sendiri.

\footnotetext{
${ }^{22}$ Fazlur Rahman, Filsafat Sadra, terj. Munir A. Mu'in, (Bandung: Pustaka, 2000), h. 167

${ }^{23}$ Fazlur Rahman, Filsafat Sadra, h. 168
} 
Prinsip pandangan para filosof sebelum Mulla Sadrayakni Ibn Sînâ dan pengikutnya adalah berdasarkan teori gerak yang dibangun berprinsip pada pengakuan bahwa gerak hanya berlaku pada kategori aksiden, sementara substasi tidak bergerak karena telah bertugas menjadi penggerak bagi aksiden. Mulla Sadradalam hal ini melakukan sebuah revolusi besar dalam sejarah filsafat dengan mengemukakan teori gerak substansi (al-harakah al-jawhariyah). Dengan pandangan ini, Mulla Sadradiakui oleh para pendukungnya telah menuntaskan perdebatan antara filosof dan teolog tentang status jasad manusia pada hari kebangkitan. Dengan prinsip gerak substansial, maka tidak ada satu entitas pun yang tetap, baik substansi maupun aksidennya. Suatu entitas memiliki dua status sekaligus yakni aktualitas dari potensi sebelumnya dan potensi untuk segera menjadi aktualitas. Karena sebenarnya pada realitas, hanya ada aktualitas. Kausalitas hanyalah konsep mental (ma'qulatu tsanî matiqî).

Mulla Sadramembagi mahiyah ke dalam dua jenis. Mahiyah pertama adalah mahiyah yang memiliki karakter murni bagi setiap entitas yang menjadikannya berbeda dengan entitas lain. Dalam pandangan tentang mahiyah seperti ini, Haqq Ta'ala tidak memiliki mahiyah karena bagi Mulla Sadra, Dia bukanlah entitas yang dapat diperhadapkan dengan entitas lain. Dengan konsekuensi seperti ini, bila menganggap Haqq Ta'ala adalah mahiyah, berarti syirik atau penyekutuan Tuhan dengan yang lain. Tidak ada apapun yang setara dengan Haqq Ta'ala. Mahiyah lain adalah mahiyah di mana mahiyah adalah entitas mutlak yang darinya segala realitas menjelma. Dalam paham mahiyah seperti ini, Haqq Ta'ala dapat disebut sebagai mahiyah. Mulla Sadramemulai pembahasan wujûd dengan wujûd murni sebagai konsep lalu barulah menjelaskan wujûd sebagai Realitas.

Munculnya tuduhan inkonsisten kepada Mulla Sadradapat dimaklumi karena awalnya dia menerima mahiyah untuk dialamatkan kepada Haqq Ta'ala yang absolut sebagaimana pandangan umum para filosof penganut ashalat al-mahiyah umumnya. Dalam hal ini Mulla Sadramenerima mahiyah sebagai Wujûd Haqq Ta'ala. Namun selanjutnya dia menolaknya dengan alasan anggapan seperti ini meniscayakan Haqq 
Ta'ala sebagai Zat yang tidak absolut. Alasannya adalah bila Haqq Ta'ala memiliki mahiyah disamping wujûd, maka wujûd-Nya adalah tambahan dari mahiyah-Nya. Padahal, wujûd Haqq Ta'ala tidak boleh diberi tambahan dari luar karena bila demikian maka wujûd Haqq Ta'ala akan menjadi berkonsekuensi tidak sempurna. Bagi Mulla Sadra, wujûd Haqq Ta'ala bukanlah mumkîn al-wujûd karena mahiyah-nya haruslah mahiyah yang ada (wujûd) secara mutlak (wajîb). Artinya, bagi Mulla Sadra, wujud Haqq Ta'ala adalah Wajib al-Wujûd.

Wajib al-Wujûd terbagi menjadi Wajib al-Wujûd lî nafsihî, yakni Wajib alWujûd yang mengada karena dirinya sendiri. Sementara wajib al-wujûd lî ghayrihî adalah wajib al-wujûd yang mengada bukan karena dirinya sendiri, tetapi mengada karena pemberian wujud oleh Wajib al-Wujûd lî nafsihî. Adapun Wajib al-Wujûd yang dinisbahkan kepada Haqq Ta'ala, tentunya adalah Wajib al-Wujûd lî nafsihî, bukan wajib al-wujûd lî ghayrihî.

Mulla Sadramengatakan wujûd pada ranah realitas eksternal benar-benar tersembunyi sekalipun hanya wujûd yang nyata pada ranah tersebut. Pada ranah eksternal, yang ditemukan hanya ragam mahiyah. Namun pada ranah mental (pikiran), wujûd menjadi benar-benar jelas dan dapat diterapkan pada segala mahiyah sebagai predikat. Sekalipun dapat diterapkan pada segala mahiyah, pada ranah mental, segala mahiyah hanya menjadi tambahan (predikasi) bagi mahiyah. Namun demikian, sekalipun tersembunyi oleh beragam mahiyah, pada realitas eksternal, wujûd adalah yang mendasar.

Sebagaimana yang dikemukakan Fazlur Rahman ${ }^{24}$, dalam pemikiran Mulla Sadra, secara konsepual, mahiyah menyebabkan wujûd adalah mustahil. Sebab dalam teori pemisahan mahiyah dan wujûd, hal ini hanya berlaku di ranah metal saja. Pada kenyataannya, yang ada hanya wujûd. Dalam hal ini, mahiyah mustahil menyebabkan wujûd karena wujûd tidak mungkin disebabkan oleh yang lain kecuali wujûd juga. Karena wujud itu tunggal, dengan demikian, wujûd tidak dapat menjadi akibat dari

\footnotetext{
${ }^{24}$ Fazlur Rahman, Filsafat Sadra, h. 168
} 
apapun. Bahkan, mahiyah adalah limitasi dari pada wujûd yang meliputi. ${ }^{25}$ Sehingga dengan demikian mustahil mahiyah menjadi sebab bagi wujûd.

Bagi Mulla Sadra, Haqq Ta'ala tidak memiliki mahiyah di samping wujûd-Nya karena bila Dia memiliki mahiyah, maka keuniversalannya tidak akan menjelmakan hal-hal lain selain-Nya, yakni wujûd yang beragam. Dan bila Haqq Ta'ala memiliki mahiyah, maka tentu Dia adalah substansi sehingga dia harus menjelma ke dalam aksiden-aksiden. Lagi-lagi argumentasi ini harus dilihat sebagai konsep mental. Karena bila tidak, kalau Haqq Ta'ala adalah Wajîb al-Wujûd, maka wujûd lainnya juga adalah Wajîb al-Wujûd. Sebab bila dianggap sebagai realitas sesungguhnya, maka tidak ada alasan satu wujûd adalah Wajîb al-Wujûd atau yang lainnya adalah mukîn al-wujûd.

Pertanyaan ini bisa muncul kepada sistem tasykîk al-wujûd Mulla Sadra: Kenapa harus ada yang lebih dahulu atau yang lebih kemudian di dalam wujûd? Sama seperti sistem kausaitas Peripatetik: Bila satu wujûd menjadi sebab yang tidak diakibatkan, kenapa wujûd lain harrus menjadi akibat, padahal dari segi status, semuanya adalah satu hal yang sama tidak lebih, tidak kurang yakni wujûd? Posisi wujûd yang semuanya sama adalah wujûd sebagai konsep. Haqq Ta'ala dan alam memiliki wujûd yang sama tanpa berbeda dengan selain-Nya adalah posisi wujûd sebagai konsep. Mulla Sadramelihat wujûd sebagai univokal, yakni kata yang memiliki acuan majemuk. Fazlur Rahman ${ }^{26}$ menjelaskan, bagi Mulla Sadra, pada hakikat realitas, wujûd memiliki beraneka ragam tingkatan sekalipun semuanya adalah wujûd. Pada sisi realitas, beragam fenomena adalah wujûd dan wujûd adalah fenomena yang beragam itu.

Persoalan lainnya adalah bila mengatakan pengetahuan tentang wujûd adalah pengetahuan primordial yang pengetahuan tentangnya bersifat langsung. Padahal setiap hal yang diketahui adalah mahiyah. Jawaban untuk persoalan ini adalah, setiap hal yang diketahui sebagai mahiyah sejatinya adalah pengetahuan tentang wujûd yang diproyeksi pikiran menjadi ragam mahiyah. Setiap pengetahuan atas tiap-tiap entitas

\footnotetext{
${ }^{25}$ Toshihiko Isutzu, Struktur Metafisika Sabzawari, (Bandung: Pustaka, 2003), h. 22

${ }^{26}$ Fazlur Rahman, Filsafat Sadra, h. 173
} 
mahiyah telah melewati pemahaman akan wujûd. Bahkan pengenalan atas ragam mahiyah adalah pengenalan kepada wujûd yang terlimitasi. Sistem pengenalan akan wujûd ini menurut Mulla Sadraadalah cara manusia mengenal Haqq Ta'ala, jadi Tuhan dikenal secara langsung oleh manusia. Tidak ada yang lebih jelas daripada Dia.

Mulla Sadramenolak mahiyah sebagai Haqq Ta'ala karena mahiyah tidak dapat diterapkan pada pluralitas mawjûdat. Sebab, setiap mahiyah haruslah sesuatu pada dirinya sendiri tidak kurang dan tidak lebih. Dengan demikian tentunya Tuhan tidak punya hubungan dengan mahiyah yang beragam kecuali hubungan-hubungan yang diproyeksi pikiran, seperti kausalitas misalnya, yang muncul dari prinsip Haqq Ta'ala haruslah sebagai pencipta atau penyebab. Dengan menjadikan wujûd sebagai sesuatu yang lebih prinsipil dibandingkan apapun, maka wujûd menjadi dapat diterapkan kepada Haqq Ta'ala sekaligus pluralitas mawjûdat.

Tema tentang keesaan Tuhan merupakan tema sentral dalam pembahasan metafisika. Ontologi memang adalah jantung filsafat. Bahkan bagi sebagian filosof, filsafat adalah ontologi, sementara epistemologi adalah cara kerja menjelaskan ontologi dan logika adalah alatnya. Dengan demikian, filsafat adalah usaha untuk Tuhan. Tetapi termonologi 'Tuhan' adalah khas teologi. Filsafat puny acara lain. Tetapi ada kesamaan dalam ketidaksamaan.

Kaum sufi, teolog dan filosof menginginkan Tuhan itu Satu, tidak ada serikat bagi-Nya. Tetapi semuanya tidak bisa memungkiri adanya aneka ragam fenomena (mawjûdat). Berbagai macam argumen muncul untuk menjelaskan posisi realitas yang beragam serta relasinya dengan Tuhan. Umumnya sufi menegaskan bahwa fenomena hanyala prroyeksi semu pikiran yang sebenarnya yang nyata adalah al-Haqq. Sementara itu teolog kebingungan karena menerima eksistensi fenomena sekaligus menerima eksistensi Tuhan sebagai yang absolut. Pandangan para teolog ini sangat rapuh karena bila menerima fenomena dengan menyandang status eksistensi sendiri yang berbeda dengan eksistensi Tuhan, maka konsekuensinya adalah menerima wujûd lain selain Tuhan yang dengan itu wujûd Tuhan menjadi terbatas. Batasnya adalah makhluk-Nya sendiri. 
Mulla Sadramencoba menengahi persoalan ini dengan menjelaskan bahwa Wajîb al-Wujûd adalah seperti subjek dan mumkîn al-wujûd adalah seperti predikat. Dalam hal ini, fenomena tetap diterima memiliki eksistensi tetapi status eksistensinya adalah mutlak dari eksistensi subjek. Umpamakan proposisi 'Joko pergi ke Solo'. Yang memiliki wujud hanyalah subjek yakni Joko, sementara 'pergi' hanyalah sebuah predikasi yang eksistensinya secara mutlak bergantung kepada eksistensi Joko. Demikianlah Mulla Sadramenentukan status fenomena segenap makhluk.

Argumentasi yang menyatakan mahiyah identik dengan wujûd sehingga mahiyah menjadi sesuatu yang mutlak sebagaimana difikirkan Fakhr al-Din al-Razi, menurut Fazlur Rahman, tidak memadai karena akal tidak dapat membayangkan lebih dari satu wujûd yang setiap wujûd, mahiyah-nya identik dengan wujûd-nya. Kalau setiap mahiyah memiliki wujûd masing-masing maka berarti wujudnya adalah tambahan bagi dirinya. Maka mahiyah seperti ini tidak dapat dialamatkan bagi Haqq Ta'ala karena Dia Maha Sempurna, Dia tidak membutukan apapun selain Diri-Nya.

Dalam kasus wujûd sebagai tambahan, mahiyah maupun wujûd-nya tidak dapat dialamatkan kepada Haqq Ta'ala karena wujud itu sendiri telah diklaim adalah dari mahiyah sekalipun setelah diteliti wujûd itu adalah datang dari luar mahiyah. Dalam menghadapi persoalan ini, seorang komentator Syihab Syihab al-Dîn Suhrawardî, Ibn Kammunâa ${ }^{27}$ memberikan solusi. Menurutnya wujûd yang datang dari luar mahiyah itu sejatinya adalah sebagai suatu kenyataan konseptual. Pola pikir seperti ini muncul karena doktrin ashalat al-mahiyah telah melekat padanya dan pengikut Syihab Syihab al-Dîn Suhrawardî. Padahal mereka sendiri telah dapat memperoleh tanda bahwa wujûd menjadi pemersatu bagi segenap entitas. Karena dogma ashalat al-mahiyah pula, sesuatu yang lainnya yang sebenarnya telah memberi sinyal tetapi ditepis adalah bahwa mereka menolak mengakui bahwa yang nyata dan menyatukan mawjûdat adalah wujûd. Karena penolakan ini, mereka mengakui adalah mahiyah yang berada pada realitas luar yang dicerap oleh pikiran. Sementara wujud dianggap sebagai konsep abstrak yang tidak nyata yang ditambahkan pada mahiyah.

\footnotetext{
${ }^{27}$ Fazlur Rahman, Filsafat Sadra, h. 179
} 
Dalam gagasan utamanya, pendiri ashalat al-mahiyah, Syihab Syihab al-Dîn Suhrawardî, telah mengklaim bahwa alam indrawi adalah illuminasi ${ }^{28}$ terakhir (tergelap) dari rentetan gradasi Cahaya.

Fazlur Rahman ${ }^{29}$ menjelaskan bahwa dalam pandangan Mulla Sadra, mahiyah menyebabkan wujûd adalah Mustahil. Pertama Mulla Sadramenegaskan bahwa yang nyata hanyalah satu hal. Sementara konsep pemisahan dan penyatuan hanyalah persepsi pikiran. Mulla Sadramenolak realitas tunggal itu adalah mahiyah karena dengan mahiyah fenomena yang beragam tidak bisa terjadi, sebab setiap entitas itu memiliki mahiyah yang berbeda dan tidak terkait satu sama lain sehingga tidak ada alasan untuk menyatakan ada persamaan antar tiap entitas kesesuatuan.

Mulla Sadra membangun fondasi ontologi berangkat dari konsep tentang realitas. Dengan ini dia menjelaskan bahwa pada setiap entitas mengandung gagasan keapaan (mahiyah) dan ke-ada-an (wujûd). Konsep ke-apa-annya hanya bisa diterapkan pada entitas tertentu dan tidak bisa diterapkan pada entitas lain. Namun konsep ke-ada-annya dapat diterapkan pada semua entitas karena setiap entitas harus nyata. Jadi dia menyatukan semua entitas adalah wujûd secara konseptual. Selanjutnya Mulla Sadra membuktikan bahwa wujûd tidak hanya mendasar (ashal) sebagai konsep tetapi juga sebagai entitas primer pada realitas eksternal. Dia menjelaskan bahwa yang dicerap pikiran adalah wujûd yang nyata. Sementara keapaannya (mahiyah) hanyalah konstruksi pikiran akibat karakteristik aslinya yakni melimitasi setiap hal. Wujûd yang menyeluruh tanpa batas, absolut, dipenggal-penggal oleh pikiran sehingga terbentuklah ragam fenomena yang berbeda antara satu dengan yang lain. Pernyataan ini menjadi alasan bahwa mahiyah muncul dari wujûd yang dilimitasi oleh cara kerja nalar $^{30}$.

Dengan penjelasan ini, Fazlur Rahman ${ }^{31}$ menegaskan bahwa hanya melalui ashalat al-wujûd saja keesaan Allah tanpa sekutu bagi-Nya dapat dijelaskan. Dengan

\footnotetext{
${ }^{28}$ Hossein Ziai, Suhrawardi dan Filsafat Illuminasi, (Jakarta: Sadra Press, 2012), h. 226

${ }^{29}$ Fazlur Rahman, Filsafat Sadra, h. 179

307 Seyyed Hossein Nasr, The Islamic Intelectual Tradition In Persia (Great Britain, Curzon Press, 1996) hal. 284

${ }^{31}$ Fazlur Rahman, Filsafat Sadra, h. 181
} 
penjelasan ini, menurutnya wujûd tidak hanya dijelaskan sebagai konsep tetapi juga yang nyata pada realitas tanpa ada batas.

Wujûd mengisi segenap realitas. Sementara mahiyah muncul sebagai limitasi wujûd. Mahiyah adalah sebagai sarana bagi pikiran untuk mengenal wujûd. Penjelasan seperti ini, meski istilah teknisnya berbeda, mirip seperti ajaran Ibn 'Arabî. Dalam rangka kritiknya terhadap Al-Ghazali, Ibn Arabi mengatakan bahwa Haqq Ta'ala tidak dapat dikenali kecuali melalui mahiyah. ${ }^{32}$ Pernyataan ini menandakan bahwa pandangan Ibn 'Arabî mirip dengan Mulla Sadra. Mereka meyakini, meski terminologi yang digunakan bernbda, bahwa mahiyah adalah konseptualisasi pikiran sebagai tanda untuk mengenal Allah.

\section{KONTRIBUSI TEOSOFI TRANSENDENTAL BAGI PENDIDIKAN AGAMA ISLAM}

Bergunakah pendidikan agama Islam di sekolah, khususnya pendidikan akidah sebagai jalan menuju tauhid? Apakah metode atau pendekatan yang digunakan di sekolah (dan madrasah) sudah ideal untuk mencapai tujuan tauhid? Bila belum, maka di mana letak persoalan yang dapat ditawarkan perbaikannya sehingga sekolah, setidaknya pendidikan agama Islam dalam pelajaran aqidah, benar-benar dapat menjadi fasilitas menuju tauhid?

Pendekatan yang digunakan di sekolah dalam pelajaran pendidikan agama Islam, khususnya tema aqidah adalah pendekatan yang sama dengan pelajaran aqidah di madrasah: teologis. Pendekatan teologis adalah pendekatan yang dianggap paling sederhana dan paling mudah dipahami dalam rangka menuju tauhid. Tauhid adalah sebuah ilmu yang dapat menghantarkan manusia untuk memahami bahwa hanya Allah saja Realitas Mutlak. Tetapi pendekatan teologis sampai akhirnya tetap saja tidak dapat menghasilkan sebuah aqidah yang benar-benar mampu memurnikan Allah.

\footnotetext{
${ }^{32} \mathrm{Ibn}$ 'Arabi, Fusus al-Hikam, Terj. Ahmad Sahidin dan Nurjannah Arianti, (Yogyakarta: Islamika, 2004) h. 124

H. 174

Eliade, Mircea, Sakral dan Profan, (Terj. Nurwanto), Yogyakarta: Fajar Pustaka Baru, 2002),
} 
Karena, pendekatan teologis tidak dapat menyangkal dualitas, setidaknya dualitas antara Tuhan dan makhluk. Padahal tujuan utama tauhid adalah sebuah kesadaran bahwa hanya Allah saja Realitas, mutlak dan tidak ada persekutuan.

Ibn 'Arabi ${ }^{33}$ sendiri mengatakan bahwa semua keilmuan manusia berpangkal dan bermuara pada manusia itu sendiri. Maksudnya, segala diskursus yang dapat dibahas manusia, termasuk tentang ketuhanan sekalipun, itu semua semata-mata untuk memperjelas posisi manusia itu sendiri. Musalnya mengkaji tentang Tuhan. Hal itu sebenarnya adalah hendak menjelaskan posisi manusia dalam rangka relasinya dengan Tuhan. Jadi, semua ilmu penyetahuan adalah untuk menjelaskan manusia ${ }^{34}$. Manusia menjadi sentra bagi semua subjek pengetahuan.

Berangkat atas kesadaran tersebut, banyak pemikir yang berusaha menjelaskan sebuah subjek seobjektif mungkin, melepaskan senralitas manusia. Mulla Sadra misalnya, dia berusaha untuk menjelaskan Tuhan bukan dengan selain Tuhan. Menurutnya Tuhan tidak bisa dikenal melalui atribut-atribut lain. Pengenalan yang benar kepada Tuhan adalam dengan mengacu kepada Tuhan sendiri ${ }^{35}$. Padahal secara umum yang terjadi, Tuhan dibahas dengan modus sifat-sifat yang cenderung humanistik: Tuhan diperkenalkan melalui sifat-sifat manusia. Cara itulah yang dilakukan sebagai pendekatan pengenalan Tuhan di sekolah dan madrasah.

Sebuah alternatif dapat diperkenalkan dalam rangka pendekatan pengenalan Tuhan dalam pelajaran pendidikan agama Islam adalah melalui teosofi transendental Mulla Sadra: Tuhan dikenal melalui Diri-Nya sendiri. Mengenal sesuatu melalui yang lain tidak akan dapat membuat yang ingin diketahui itu dapat diketahui. Oleh karena itu, tawaran Mulla Sadra layak dipertimbangkan. Karena selama ini di sekolah, Tuhan

33 Miswari "Filosofi Komunikasi Spiritualitas: Huruf Sebagai Simbol Ontologi dalam Mistisme Ibn 'Arabî”, Jurnal Al-Hikmah, Vol. IX No. 14, 2017.

${ }^{34}$ Eliade, Mircea, Sakral dan Profan, (Terj. Nurwanto), Yogyakarta: Fajar Pustaka Baru, 2002), h. 174.

${ }^{35}$ Reza Akbarian, Trans-Subtantial Motion and Its Philosophical Consequencess di dalam Mullâ Sadrâ and Transendent Philosophy; Islam-West Philosophical Dialog, The Papers presented at The World Congress Mullâ Sadrâ, (Teheran; Shadra Islamic Philosophical Institute Publication, May, 1999) h. 187-188. 
diperkenalkan melalui tribut-atribut manusia. Tuhanpun dipahami sebagai sebuah sosok. Dan tentunya ini bukan tujuan yang diharapkan dari pendidikan agama Islam.

Melalui sistem ashalat al-wujûd dan tasykik al-wujûd, Mulla Sadra merumuskan bagaimana Tuhan harus dipahami sebagai dasar bagi seluruh entitas yang ada di alam semesta. Semua makhluk harus dipahami sebagai satu kesatuan wujûd yang sama dengan wujûd Tuhan dengan intensitas wujûd yang berbeda. Konsep ini konsisten dengan alur penalaran logika filosof yang melihat wujûd secara konseptual adalah univokal. Wujud itu secara konseptual adalahkonsep tunggal yang acuannya juga harus satu entitas. Sementara pada realitas wujûd, wujûd Tuhan dengan wujûd makhluk berbeda dari sisi intensitas. Prinsip ini juga dapat dipahami melalui analogi relasi antara subjek dan predikat dalam sebuah kalimat.

Entitas yang ril sebenarnya adalah subjek, sementara predikat semata-mata hanyalah konsep tentang suatu yang digunakan untuk menjelaskan subjek. Analogi ini dapat dimaknai dalam pendidikan aqidah yaitu, bahwa makhluk-makhluk yang beragam sebenarnya adalah bentuk konseptual dari kaindahan Ilahi. Predikat-predikat negatif muncul dari persepsi manusia agar predikat-predikat positif dapat dipahami. Pengasih, Penyayang, Pengampun, sebenarnya hanyalah modus pemahaman untuk memahami Allah. Dan sebenarnya predikat-predikat itu adalah konsep-konsep tentang kondisi yang hanya dapat dipahami ketika disandang makhluk. Dan hal yang paling penting dari kasus ini adalah, semua sifat itu hanyalah predikat-predikat yang sama sekali tidak berguna kecuali untuk mengenal subjeknya.

Bila posisi makhluk dengan Tuhannya adalah seperti posisi antara subjek dengan predikat, maka pendidikan aqidah harus mampu sebaik mungkin memberikan pemahaman bahwa Tuhan itu bukanlah suatu sosok yang berada entah di mana sedang mengontrol dan mengawasi manusia dengan garangnya. Tuhan adalah zat yang tidak dapat dipisahkan dengan manusia sebagaimana tidak dapat dipisahkannya predikat dari subjek. Kedekatan yang tiada berjarak ini harus mampu dipahami dengan benar sehingga terbangun kesadaran tauhid yang benar. Sebab perkara ini sangat sensitif. 
Bila gagal menghayatinya, maka alih-alih menghadirkan tauhid yang benar, malah menjerumuskan pada kesesatan.

Pendidikan yang baik tentang Tuhan harus mempersiapkan bekal yang baik bagi anak didik. Apalagi subjeknya rumit dan urgen seperti. Pelajaran aqidah. Mengikuti alur sistem filsafat Mulla Sadra tentang tauhid, wujûd Tuhan harus diperjelas antara konsep dan realitasnya. Ini penting agar tidak menciptakan kebingungan. Misalnya konsep wujud sangat ditekankan Mulla Sadra untuk diperjelas perbedaannya dengan realitas wujud. Karena dalam ranah konseptual, wujud itu bersifat univokal, satu konsep yang hanya memiliki satu acuan. Univokasi konsep wujûd tidak boleh dianggap sebagai realitas. Karena pada realitas, wujûd itu bergradasi $^{36}$.

Wujûd sebagai satu kesatuan yang bergradasi sehingga tampak beragam menjadi sangat penting dalam pelajaran aqidah. Karena hanya skema ini yang dapat menjelaskan secara rasional bagaimana Tuhan itu tidak terbatas. Karena bila tidak, maka wujûd Tuhan akan menjadi terbatas. Apa batas bagi wujûd Tuhan yaitu makhluk. Gradasi realitas wujud sebagai solusi bagi pelajaran aqidah yang konsisten dengan rasio. Sinergitas antara doktrin teologis dengan rasionalitas menjadi harmonis dalam pemikiran Mulla Sadra ${ }^{37}$.

Pendekatan wujûd sebagai pelajaran aqidah tidak hanya memuaskan nalar tetapi juga sebenarnya memiliki metode yang mudah untuk menciptakan pemahaman yang jelas. Harus dipahami wujûd sebagai sesuatu yang tunggal, primer dan meliputi. Sementara mahiyah hanyalah modul bagi rasionalitas untuk mengenal wujûd. Bila dapat disampaikan dengan baik, maka pendekatan ini dapat menjadi sebuat tawaran bagi pendekatan aqidah sehingga pola pengajaran aqidah dengan cara-cara sebelumnya yang meninggalkan kebingungan dapat ditinggalkan.

36 Mulyani, Gerak Trans-Substansial dan Implikasinya Terhadap Relasi Jiwa dan Tubuh dalam Al-Hikmah Al-Muta'alliyah, h. 9

${ }^{37}$ Seyyed Hossein Nasr, The Islamic Intelectual Tradition in Persia, h. 279. 
Tidak hanya konsep-konsep teknisnya, pemikiran filsafat Mulla Sadra juga dapat bedayaguna bagi penerapan nilai-nilai pendidikan agama Islam. Mulyadhi Kartanegara misalnya, dia menjadikan teori gradasi wujud Mulla Sadra sebagai basis penyusunan integrasi ilmu-ilmu keagamaan dan ilmu-ilmu non-keagamaan ${ }^{38}$. Abdul Munir Mulkan juga menggunakan teori filsafat Mulla Sadra sebagai basis penyusunan konsep pendidikan berbasis transendetalitas ${ }^{39}$.

Sebenarnya filsafat Mulla Sadra sangat berdayaguna bagi penuntasan masalahmasalah yang dihadapi dalam dunia pendidikan untuk mendidik jiwa manusia. Tetapi banyak tantangan untuk itu.

\section{E. KESIMPULAN}

Filsafat adalah sebuah diskursus yang lmasih langka di Indonesia. Pandangan masyarakat, bahkan sebagian besar kaum terpelajar masih sangat negative terhadap filsafat. Akibatnya, Indonesia hanya mampu mengkonsumsi konsep-konsep praktis hasil gagasan filosofis yang dihasilkan oleh filosof dari Barat. Umumnya gagasangagasan dari Barat tidak sesuai dengan nilai berkehidupan masyarakat Idonesia. Untuk itu, dibutuhkan sebuah gagasan yang palong sesuai dengan fitrah kemanusiaan karena gagasan demikian punya kemungkinan besar untuk dapat diterapkan di manapun. Untuk itulah, gagasan filosof besar Mulla Sadra patut dipertimbangkan untuk dapat dijadikan solusi untuk mengatasi persoalan kemanusiaan di Indonesia, khususnya bidang pendidikan.

Sebenarnya masyarakat Indonesia di setiap daerah memiliki kearifan masingmasing yang dapat diejawantah ke dalam system pendidikannya tetapi pemahaman nasionalisme yang keliru telah membuat kearifan-kearifan local terpaksa ditinggalkan. Semuanya dipaksa mengikuti satu aturan yang diklaim sebagai prinsip ideal nasionalisme. Tetapi kesalahan itu belum benar-benar terlambat. Pendidikan di Indonesia masih punya peluang untuk diselamatkan.

\footnotetext{
${ }^{38}$ Mulyadhi Kartanegara, Integrasi Ilmu: Sebuah Rekonstruksi Holistik, (Bandung: Arasy, 2005).

${ }^{39}$ Tanthowi, (ed.) Begawan Muhammadiyah, (Jakarta: PSAP, 2005).
} 
Bidang utama pendidikan yang penting untuk diselamatkan adalah agama. Karena spiritualitas merupakan tuntutan utama bagi manusia dalam berkehadupan. Sekaya apapun seseorang, dia akan tetap mere=asakan kegelisahan dan penderitaan bila tuntutan spiritualitas tidak dipenuhi. Sebaliknya walaupun seseorang hidup sederhana, tetapi bila tuntutan spiritualitasnya terpenuhi, maka di dapat hidup bahagia. Untuk itulah spiritualitas menjadi hal yang paling urgen dalam pendidikan.

Sekiranya tawaran penulis untuk mengambil nilai-nilai dari ajaran Mulla sadra dapat dipertimbangkan sebagai alternative bagi pendidikan, khususnya pendidikan agama Islam karena belakangan, paradigma-paradigma yang ditawarkan dalam pembelajaran agama Islam umumnya mengarah pada radikalisme. Ini sangat berbahaya karena memiliki peluang besar mengarah kepada ekstrimisme. Harmonisme menjadi mustahil. Padahal kita hidup di negara yang beragam agama. Untuk itu nilanilai rasional dan spiritual dari gagasan Mulla Sadra patut dilirik sebagai alternate.

\section{DAFTAR PUSTAKA}

'Arabi, Ibn, Fusus al-Hikam, alih bahasa: Ahmad Sahidin dan Nurjannah Arianti, Yogyakarta: Islamika, 2004.

Akbarian, Reza, Trans-Subtantial Motion and Its Philosophical Consequencess di dalam Mullâ Sadrâ and Transendent Philosophy; Islam-West Philosophical Dialog, The Papers presented at The World Congress Mullâ Sadrâ, Teheran: Shadra Islamic Philosophical Institute Publication, May, 1999.

Chittick,William C., Dunia Imajinal Ibnu 'Arabi, Surabaya: Risalah Gusti, 2001

Eliade, Mircea, Sakral dan Profan, (Terj. Nurwanto), Yogyakarta: Fajar Pustaka Baru, 2002.

Isutzu, Toshihiko, StrukturMetefisika Sabzawari, Bandung: Pustaka, 2003

Kartanegara, Mulyadhi, Integrasi Ilmu: Sebuah Rekonstruksi Holistik, Bandung: Arasy, 2005.

Miswari "Filosofi Komunikasi Spiritualitas: Huruf Sebagai Simbol Ontologi dalam Mistisme Ibn 'Arabî', Jurnal Al-Hikmah, Vol. IX No. 14, 2017. 
Mulyani, Gerak Trans-Substansial dan Implikasinya Terhadap Relasi Jiwa dan Tubuh dalam Al-Hikmah Al-Muta'alliyah, Tesis, Jakarta: ICAS-Paramadina, 2014.

Muthahhari, Murtadha, Filsafat Hikmah; Pengantar Pemikiran Sadra, Diterjemahkan Oleh Tim Penerjemah Mizan, Bandung: Mizan, 2002.

Nasr, Seyyed Hossein. (ed), Ensiklopedi Tematis Filsafat Islam: Buku kedua, Bandung, Mizan, 2003.

The Islamic Intelectual Tradition in Persia, Great Britain: TJ Press Limited, 1996.

Rahman, Fazlur Filsafat Sadra, terjemah oleh Munir A. Mu'in, Bandung: Pustaka, 2000

Tanthowi, (ed.) Begawan Muhammadiyah, Jakarta: PSAP, 2005.

Yazdi, Mehdi Haeri, Menghadirkan Cahaya Tuhan: Epistemologi Illuminasionis dalam Filsafat Islam, Bandung: Mizan, 2003

Nur, Muhammad Wahdah al-Wujûd Ibn 'Arabi dan Filsafat Wujud Sadra, Makassar: Chamran Press, 2012

Ziai, Hossein Suhrawardi dan Filsafat Illuminasi, Jakarta: Sadra Press, 2012 